\title{
Risk factors for surgical site infection following lumbar spinal surgery: a meta-analysis
}

This article was published in the following Dove Press journal:

Therapeutics and Clinical Risk Management

\author{
Lin Zhang \\ Er-Nan Li \\ Department of Spine Surgery, Beijing \\ Shijitan Hospital, Capital Medical \\ University, Beijing, China
}

Objective: To identify risk factors for surgical site infection (SSI) in patients who had undergone lumbar spinal surgery.

Methods: Studies published in PubMed, Web of Science, and Embase were systematically reviewed to determine risk factors for SSI following lumbar spinal surgery. Results are expressed as risk ratios (RRs) with 95\% CIs and weighted mean difference (WMD) with 95\% CI. A fixed-effect or random-effect model was used to pool the estimates according to heterogeneity among the studies included.

Results: Sixteen studies involving 13,393 patients were included in this meta-analysis. Pooled estimates suggested that diabetes (RR 2.19, 95\% CI 1.43-3.36; $P<0.001$ ), obesity (RR 2.87, 95\% CI 1.62-5.09; $P<0.001$ ), BMI (WMD $1.32 \mathrm{~kg} / \mathrm{m}^{2}, 95 \%$ CI 0.39-2.25; $P=0.006$ ), prolonged operating time (WMD 24.96 minutes, $95 \%$ CI 14.77-35.15; $P<0.001$ ), prolonged hospital stay (WMD 2.07 days, 95\% CI 0.28-3.87; $P=0.024$ ), hypertension (RR 1.28, 95\% CI 1.08-1.52; $P=0.005)$, and previous surgery (RR $2.06,95 \%$ CI $1.39-3.06 ; P<0.001)$ were independent risk factors for SSI in patients who had undergone lumbar spine surgery. Current smoking (RR 0.89, 95\% CI 0.75-1.06; $P=0.178)$, American Society of Anesthesiologists grade $>2$ (RR 2.63, 95\% CI $0.84-8.27 ; P=0.098$ ), increased age (WMD 1.43 years, $95 \% \mathrm{CI}-1.15$ to $4.02 ; P=0.278$ ), COPD (RR 1.21, 95\% CI 0.68-2.17; $P=0.521$ ), cardiovascular disease (RR 1.63, 95\% CI 0.40-6.70; $P=0.495$ ), rheumatoid arthritis (RR $1.76,95 \%$ CI $0.53-5.90 ; P=0.359$ ), and osteoporosis (RR $1.91,95 \%$ CI $0.79-4.63 ; P=0.152$ ) were not risk factors for postoperative SSI.

Conclusion: Our results identified several important factors that increased the risk of postoperative SSI. Knowing these risk factors, surgeons could adequately analyze and evaluate risk factors in patients and then develop prevention measurements to reduce the rate of SSI.

Keywords: lumbar spinal surgery, surgical site infection, risk factors, meta-analysis

\section{Introduction}

Surgical site infection (SSI) is one of the most serious complications following lumbar spine surgery during the early postoperative stage. SSI rates have been reported to be $0.7 \%-12.0 \%{ }^{1,2}$ Despite several interventions in clinical practice, including the use of prophylactic antibiotics, improvements in surgical techniques, and postoperative care, SSI continues to affect patients after lumbar surgery. ${ }^{3,4}$ SSI usually requires surgical debridement, which leads to higher postoperative morbidity and mortality. ${ }^{5-7}$ This would increase the duration of hospital stay, reoperation rates, and additional treatment costs. ${ }^{5-7}$ Therefore, determining risk factors for postoperative SSI and seeking methods to reduce SSI rates are very necessary.

There have been several studies to investigate postoperative SSI risk factors, such as increased age,${ }^{8}$ obesity,,${ }^{9,10}$ diabetes,${ }^{8,10}$ smoking, ${ }^{10}$ previous infection, ${ }^{11}$ prolonged operating time, ${ }^{12}$ prolonged hospital stay, ${ }^{13}$ and admission from a health care facility. ${ }^{14}$
Correspondence: Lin Zhang Department of Spine Surgery, Beijing Shijitan Hospital, Capital Medical University, No. I0, Tieyi Road, Yangfangdian, Haidian District, Beijing 100038, China

$\mathrm{Tel}+8618910160203$

Email18910160203@163.com 
However, the results of these studies were inconsistent. In order to systematically assess the most important risk factors for SSI following lumbar spinal surgery, we conducted this meta-analysis. Based upon identified risk factors, we can deduce preventive strategies to reduce the risk for SSI, thereby decreasing the morbidity, mortality, and health care costs.

\section{Methods}

\section{Search strategy}

This meta-analysis was performed according to the PRISMA (preferred reporting items for systematic reviews and metaanalyses) statement. ${ }^{15}$ We did a comprehensive search on PubMed, Embase, and Web of Science from their inception to May 11, 2018. Search items were (("lumbosacral region" [MeSH terms] OR ("lumbosacral" [all fields] AND "region" [all fields]) OR "lumbosacral region" [all fields] OR "lumbar" [all fields]) AND ("surgery" [subheading] OR "surgery" [all fields] OR "surgical procedures, operative" [MeSH terms] OR ("surgical" [all fields] AND "procedures" [all fields] AND "operative" [all fields]) OR "operative surgical procedures" [all fields] OR "surgery" [all fields] OR "general surgery" [MeSH terms] OR ("general" [all fields] AND "surgery" [all fields]) OR "general surgery" [all fields])) AND ("surgical wound infection" [MeSH terms] OR ("surgical" [all fields] AND "wound" [all fields] AND "infection" [all fields]) OR "surgical wound infection" [all fields] OR ("surgical" [all fields] AND "site" [all fields] AND "infection" [all fields]) OR "surgical site infection" [all fields]) AND ("risk factors" [MeSH terms] OR ("risk" [all fields] AND "factors" [all fields]) OR "risk factors" [all fields] OR ("risk" [all fields] AND "factor" [all fields]) OR "risk factor" [all fields]). There was no limitation on language or publication type. Moreover, we also manually searched the references of the studies and reviews included to identify other potentially eligible studies.

\section{Inclusion criteria}

Two independent investigators performed the literature search, literature review (title/abstract review, full-text review, and included eligible studies). Any disagreement between them was resolved by discussion and consensus. All studies that investigated risk factors for postoperative SSI after lumbar spinal surgery were considered eligible for data analysis. We included the studies that met inclusion criteria of randomized controlled trial, cohort study, or case-control study, adult patients who had undergone lumbar spinal surgery, and presence of risk factors for postoperative SSI.

\section{Data extraction and quality assessment}

Two independent investigators performed the data extraction. Data extracted included country of study, number of patients in SSI group and non-SSI group, baseline characteristics, and outcomes. We used the modified Newcastle-Ottawa Scale $(\mathrm{NOS})^{16}$ to evaluate the quality of observational studies (cohort study, case-control study). This method consists of three items: patient selection, comparability of experimental and control groups, and assessment of outcomes of interest. ${ }^{16}$ The total score is 9 , and higher scores indicate better quality. Any study is considered of high quality if the NOS score is $>5$ points. ${ }^{16}$

\section{Statistical analysis}

Dichotomous variables are expressed as RRs with 95\% CIs and continuous variables weighted mean difference (WMD) with 95\% CIs. We used a fixed-effect model (Mantel-Haenszel method) ${ }^{17}$ or random-effect model (DerSimonian-Laird method) ${ }^{18}$ to pool all data according to heterogeneity across the included studies. Heterogeneity among the studies was assessed using the $I^{2}$ statistic, ${ }^{19}$ where $I^{2}>50 \%$ was considered substantial heterogeneity. ${ }^{19}$ When significant heterogeneity was identified, sensitivity analysis was performed to explore the potential source of heterogeneity. Publication bias was evaluated by Begg's ${ }^{20}$ and Egger's ${ }^{21}$ test. We considered $P<0.05$ statistically significant, except where otherwise specified. All statistical analyses were performed using Stata version 12.0 (StataCorp, College Station, TX, USA).

\section{Results \\ Study identification and selection}

Figure 1 shows the article-screening and -selection process for inclusion in this study. The initial search yielded 896 studies. Of these, 512 were excluded for duplicate records and 362 excluded after the review of title/abstract. Then, 22 studies were left for full-text review. Among these, six were excluded: four for not providing eligible data, ${ }^{22-25}$ and two that were unrelated to our topic. ${ }^{26,27}$ Finally, 16 studies ${ }^{28-43}$ met the inclusion criteria and were included in this meta-analysis.

\section{Study characteristics and quality assessment}

The main characteristics of included studies are presented in Table 1. These were published between 2003 and 2018. The total sample size was 13,393, of which 704 were in the SSI group and 12,689 the non-SSI group. Among these studies, nine $28,31,32,35-37,40,41,43$ were conducted in the US, two in 


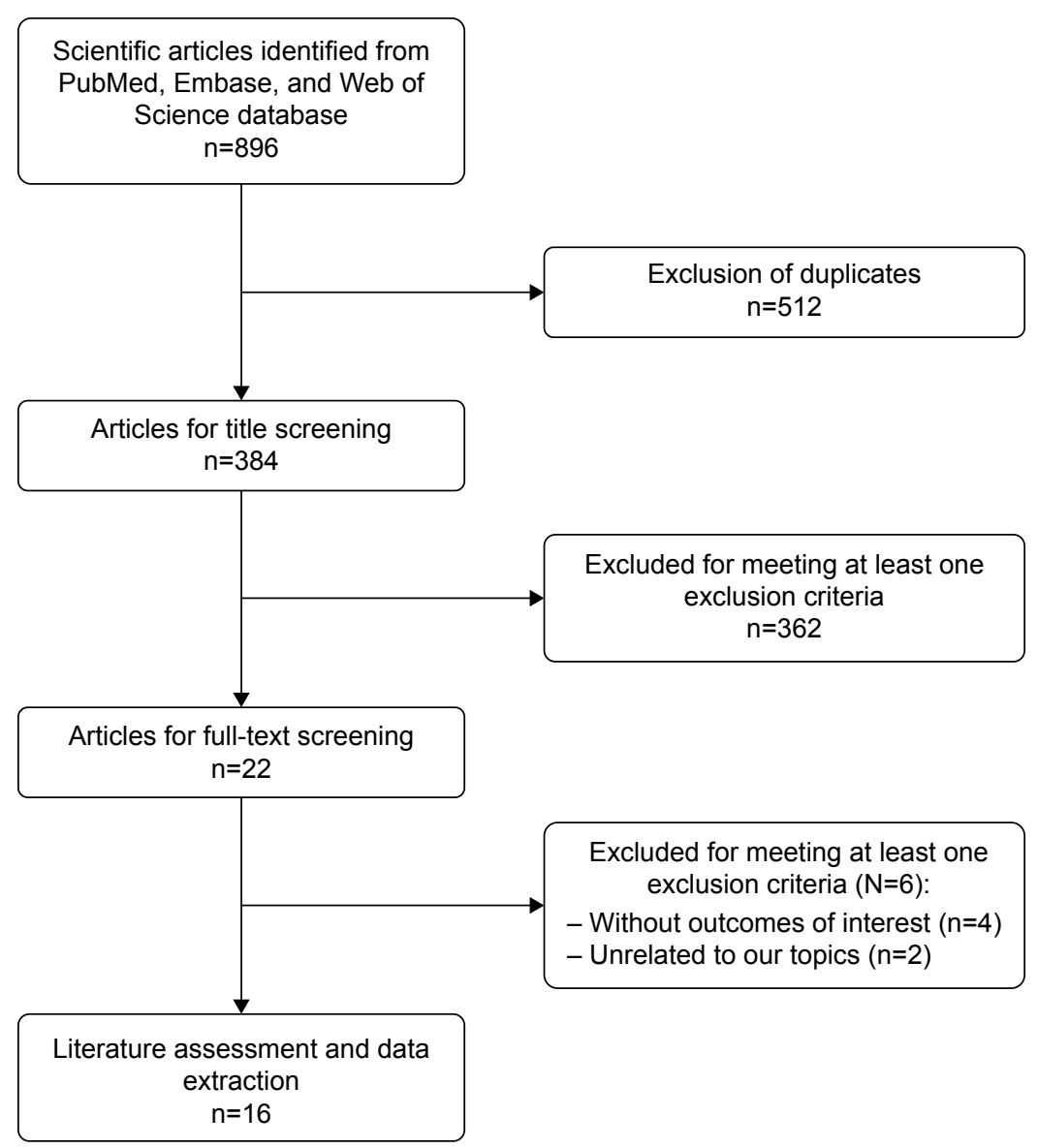

Figure I Eligibility of studies for inclusion in meta-analysis.

Table I Baseline characteristics of patients in trials included

\begin{tabular}{|c|c|c|c|c|c|c|}
\hline Study & Country & Design & $\begin{array}{l}\text { SSI } \\
\text { group }\end{array}$ & $\begin{array}{l}\text { Non-SSI } \\
\text { group }\end{array}$ & Surgery & $\begin{array}{l}\text { NOS } \\
\text { score }\end{array}$ \\
\hline Lim et $\mathrm{al}^{28}$ & USA & Retrospective case-control & 173 & 3,180 & Single-level lumbar fusion surgery & 7 \\
\hline Kim et $\mathrm{al}^{29}$ & South Korea & Retrospective case-control & 30 & $|, 80|$ & $\begin{array}{l}\text { Posterior lumbar interbody } \\
\text { fusion }\end{array}$ & 7 \\
\hline Habiba et $\mathrm{al}^{30}$ & Norway & Retrospective case-control & 40 & ।,732 & $\begin{array}{l}\text { Lumbar disc herniation } \\
\text { without laminectomy or fusion }\end{array}$ & 7 \\
\hline $\begin{array}{l}\text { Koutsoumbelis } \\
\text { et } \mathrm{al}^{31}\end{array}$ & USA & Retrospective case-control & 84 & 168 & $\begin{array}{l}\text { Posterior lumbar } \\
\text { instrumented arthrodesis }\end{array}$ & 5 \\
\hline Lee et $\mathrm{a}^{32}$ & USA & Retrospective case-control & 15 & 134 & Lumbar spine surgery & 5 \\
\hline Liu et $\mathrm{a}^{33}$ & China & Retrospective case-control & 64 & 192 & Posterior lumbar spinal surgery & 6 \\
\hline Ogihara et $\mathrm{al}^{34}$ & Japan & Prospective cohort study & 24 & 2,712 & Posterior lumbar spinal surgery & 7 \\
\hline Chaichana et a $\left.\right|^{35}$ & USA & Retrospective case-control & 37 & 780 & $\begin{array}{l}\text { Posterior instrumented } \\
\text { lumbar fusion }\end{array}$ & 5 \\
\hline Mehta et al ${ }^{16}$ & USA & Retrospective case-control & 24 & 274 & Lumbar spinal fusion & 7 \\
\hline Petilon et $\mathrm{al}^{37}$ & USA & $\begin{array}{l}\text { Propensity score-matched } \\
\text { case-control study }\end{array}$ & 30 & 30 & $\begin{array}{l}\text { Instrumented lumbar } \\
\text { spinal fusion }\end{array}$ & 6 \\
\hline Falavigna et $\mathrm{al}^{38}$ & Brazil & Prospective cohort study & 13 & 39 & Lumbar arthrodesis & 7 \\
\hline Schimmel et a ${ }^{39}$ & the Netherlands & Retrospective case-control & 36 & 135 & Lumbar spinal fusion & 5 \\
\hline Chen et $\mathrm{al}^{40}$ & USA & Retrospective case-control & 30 & 165 & Lumbar spinal fusion & 6 \\
\hline Blam et $\mathrm{al}^{41}$ & USA & Retrospective cohort & 24 & 232 & Lumbar spinal fusion & 7 \\
\hline Lai et $\mathrm{al}^{42}$ & China & Retrospective case-control & 26 & 897 & Lumbar spine surgery & 6 \\
\hline Haleem et $\mathrm{al}^{43}$ & USA & Retrospective case-control & 54 & 218 & Lumbar spine surgery & 6 \\
\hline
\end{tabular}

Abbreviations: NOS, Newcastle-Ottawa Scale; SSI, surgical site infection. 
China, ${ }^{33,42}$ and one each in South Korea, ${ }^{29}$ Norway, ${ }^{30}$ Japan, ${ }^{34}$ Brazil, ${ }^{38}$ and the Netherlands. ${ }^{39}$ Most studies were performed with a retrospective case-control design, except three, which were prospective ${ }^{34,38}$ or retrospective ${ }^{41}$ cohort design. All patients had undergone lumbar fusion surgery or posterior lumbar spinal surgery. NOS scores ranged from 5 to 7 , which indicated that these studies were of high quality.

\section{Risk factors}

Sex

The most important risk factors for SSI are presented in Table 2. Eleven studies investigated the relationship between sex and postoperative SSI. ${ }^{28-31,33,34,36-39,43}$ The pooled estimate showed that males had a significantly lower risk of developing postoperative SSI compared with females (RR 0.88, 95\% CI $0.80-0.97 ; P=0.008$; Figure 2$)$. There was no significant heterogeneity among the studies $\left(I^{2}=49.2 \%, P=0.032\right)$.

\section{Increased age}

Eight studies assessed the relationship between increased age and postoperative SSI. ${ }^{32-35,38,41-43}$ The pooled result suggested that patients with SSI were older than those without (WMD 1.43 years, 95\% CI 1.15-4.02; Figure 3); however, this difference was not significant $(P=0.2777)$. This indicated that increased age was not a significant risk factor for SSI.

Table 2 Pooled estimates of RR (WMD) a obtained from metaanalysis of risk factors of SSI following lumbar spine surgery

\begin{tabular}{|c|c|c|c|}
\hline & $\mathbf{R} \mathbf{R}$ & $95 \% \mathrm{Cl}$ & $P$-value \\
\hline Male sex & 0.88 & $0.80-0.97$ & 0.008 \\
\hline Diabetes & 2.19 & $1.43-3.36$ & $<0.001$ \\
\hline Current smoking & 0.89 & $0.75-1.06$ & 0.178 \\
\hline ASA grade $>I I$ & 2.63 & $0.84-8.27$ & 0.098 \\
\hline Obesity & 2.87 & $1.62-5.09$ & $<0.001$ \\
\hline Increased age $\mathrm{a}^{\mathrm{a}}$ & 1.43 & -1.15 to 4.02 & 0.2777 \\
\hline $\mathrm{BMI}^{\mathrm{a}}$ & 1.32 & $0.39-2.25$ & 0.006 \\
\hline Duration of surgery ${ }^{\mathrm{a}}$ & 24.96 & $14.77-35.15$ & $<0.001$ \\
\hline Duration of hospital stay ${ }^{a}$ & 2.07 & $0.28-3.87$ & 0.024 \\
\hline Estimated blood loss ${ }^{\mathrm{a}}$ & 106.90 & -65.14 to 278.53 & 0.224 \\
\hline COPD & 1.21 & $0.68-2.17$ & 0.521 \\
\hline Hypertension & 1.28 & $1.08-1.52$ & 0.005 \\
\hline Cardiovascular disease & 1.63 & $0.40-6.70$ & 0.495 \\
\hline Rheumatoid arthritis & 1.76 & $0.53-5.90$ & 0.359 \\
\hline Osteoporosis & 1.91 & $0.79-4.63$ & 0.152 \\
\hline Allogeneic blood transfusion & 1.39 & $0.59-3.27$ & 0.457 \\
\hline Previous surgery & 2.06 & $1.39-3.06$ & $<0.001$ \\
\hline Implanted instrument & 1.41 & $1.19-1.66$ & 0.533 \\
\hline Sleep apnea & 1.00 & $0.18-5.35$ & 1.00 \\
\hline Hypercholesterolemia & 1.07 & $0.70-1.62$ & 0.764 \\
\hline
\end{tabular}

Note: aResults expressed as WMD with $95 \% \mathrm{Cl}$.

Abbreviations: WMD, weighted mean difference; SSI, surgical site infection; ASA, American Society of Anesthesiologists; BMI, body-mass index.

\section{Diabetes}

Twelve studies investigated the relationship between diabetes and postoperative SSI. ${ }^{28,29,31-36,39,40,42,43}$ The pooled estimate suggested that diabetes patients had a 2.19-fold increased risk of developing SSI compared with those without diabetes (RR $2.19,95 \%$ CI 1.43-3.36; $P<0.00$; Figure 4). Heterogeneity was significant $\left(I^{2}=90.1 \%, P<0.001\right)$, and thus we conducted sensitivity analysis. When we excluded a study with a relatively small sample $(\mathrm{n}=149),{ }^{32}$ the pooled estimate of the remaining studies did not change substantially (RR 2.23, 95\% CI 1.71-3.43; $P<0.001)$, but heterogeneity was still present $\left(I^{2}=89.5 \%, P<0.001\right)$. Furthermore, we excluded studies one at a time, and overall estimates changed slightly, but heterogeneity was still observed.

\section{Current smoking}

Nine studies investigated the relationship between current smoking and postoperative SSI. ${ }^{28,30-32,34,35,37,39,43}$ Pooled estimates showed that current smokers had a comparable rate of postoperative SSI than nonsmokers (RR $0.89,95 \%$ CI $0.75-1.06 ; P=0.178$; Figure 5). This indicated that current smoking did not increase the risk of postoperative SSI in patients with lumbar spine surgery. Heterogeneity was not significant $\left(I^{2}=46.2 \%, P=0.062\right)$.

\section{Obesity}

Six studies investigated the relationship between obesity and postoperative SSI. ${ }^{30-32,35,36,43}$ The pooled result showed that obesity patients had a 2.87 -fold increased risk of SSI than those of normal weight (RR 2.87, 95\% CI 1.62-5.09; $P<0.001)$. This indicated that obesity was a significant risk for SSI. There was no significant heterogeneity among the studies $\left(I^{2}=43.4 \%, P=0.078\right)$.

\section{ASA grade $>2$}

Four studies investigated the relationship between American Society of Anesthesiologists (ASA) grade and postoperative SSI. ${ }^{28,30,34,43}$ Pooled estimates suggested that patients with ASA grade $>2$ had a similar rate of postoperative SSI compared with those with ASA grade 1-2 (RR 2.63, 95\% CI $0.84-8.27 ; P=0.098)$. This demonstrated that ASA grade $>2$ did not increase the risk of postoperative SSI. Heterogeneity was not significant $\left(I^{2}=45.6 \%, P=0.073\right)$.

\section{BMI}

Nine studies investigated the relationship between bodymass index (BMI) and postoperative SSI. $30,32,34,36,37,39,41-43$ 


\begin{tabular}{|c|c|c|}
\hline Study ID & $\operatorname{RR}(95 \% \mathrm{Cl})$ & $\%$ Weight \\
\hline Lim S (2018) & $0.78(0.64-0.96)$ & 29.89 \\
\hline Kim JH (2015) & $0.78(0.56-1.09)$ & 8.05 \\
\hline Habiba S (2017) & $0.95(0.72-1.26)$ & 9.02 \\
\hline Koutsoumbelis S (2011) & $0.73(0.52-1.01)$ & 10.63 \\
\hline Liu JM (2017) & $1.00(0.84-1.19)$ & 13.75 \\
\hline Ogihara S (2015) & $1.31(1.04-1.65)$ & 5.43 \\
\hline Mehta Al (2012) & $0.94(0.66-1.33)$ & 5.46 \\
\hline Petilon JM (2012) & $0.67(0.32-1.39)$ & 2.39 \\
\hline Falavigna A (2011) & $1.20(0.59-2.44)$ & 1.50 \\
\hline Schimmel JJP (2010) & $1.14(0.76-1.70)$ & 4.70 \\
\hline Haleem A (2016) & $0.80(0.57-1.12)$ & 9.18 \\
\hline Overall $\left(I^{2}=49.2 \%, P=0.032\right)$ & $0.88(0.80-0.97)$ & 100 \\
\hline $\begin{array}{c}1 \\
0.319\end{array}$ & 3.14 & \\
\hline
\end{tabular}

Figure 2 Forest plot showing the relationship between male sex and postoperative surgical site infection.

Pooled estimates suggested that patients with high BMI values had a higher risk of developing SSI than those with normal BMI (WMD $1.32 \mathrm{~kg} / \mathrm{m}^{2}, 95 \%$ CI $0.39-2.25$; $P=0.006$ ). This indicated that BMI was a significant risk factor for postoperative SSI. Heterogeneity was not significant $\left(I^{2}=48.3 \%, P=0.067\right)$.

\section{Duration of surgery}

Ten studies investigated the relationship between duration of surgery and postoperative SSI. ${ }^{29-33,37,39,41-43}$ Pooled estimates suggested that patients with longer surgeries were more likely to develop SSI (WMD 24.96 minutes, 95\% CI 14.77-35.15; $P<0.001)$. This indicated that prolonged surgery was an

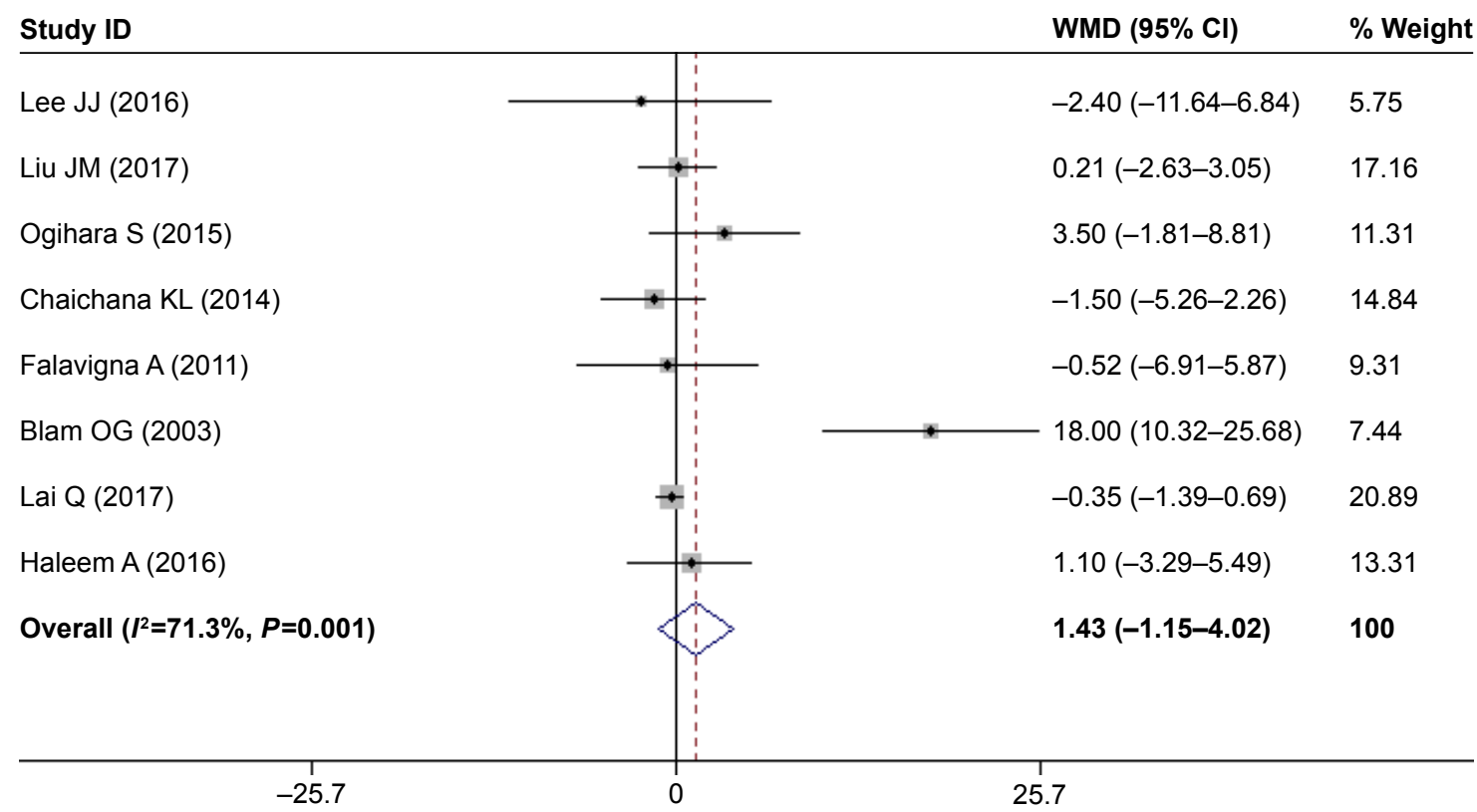

Figure 3 Forest plot showing relationship between increased age and postoperative surgical site infection. Note: Weights are from random-effects analysis. 


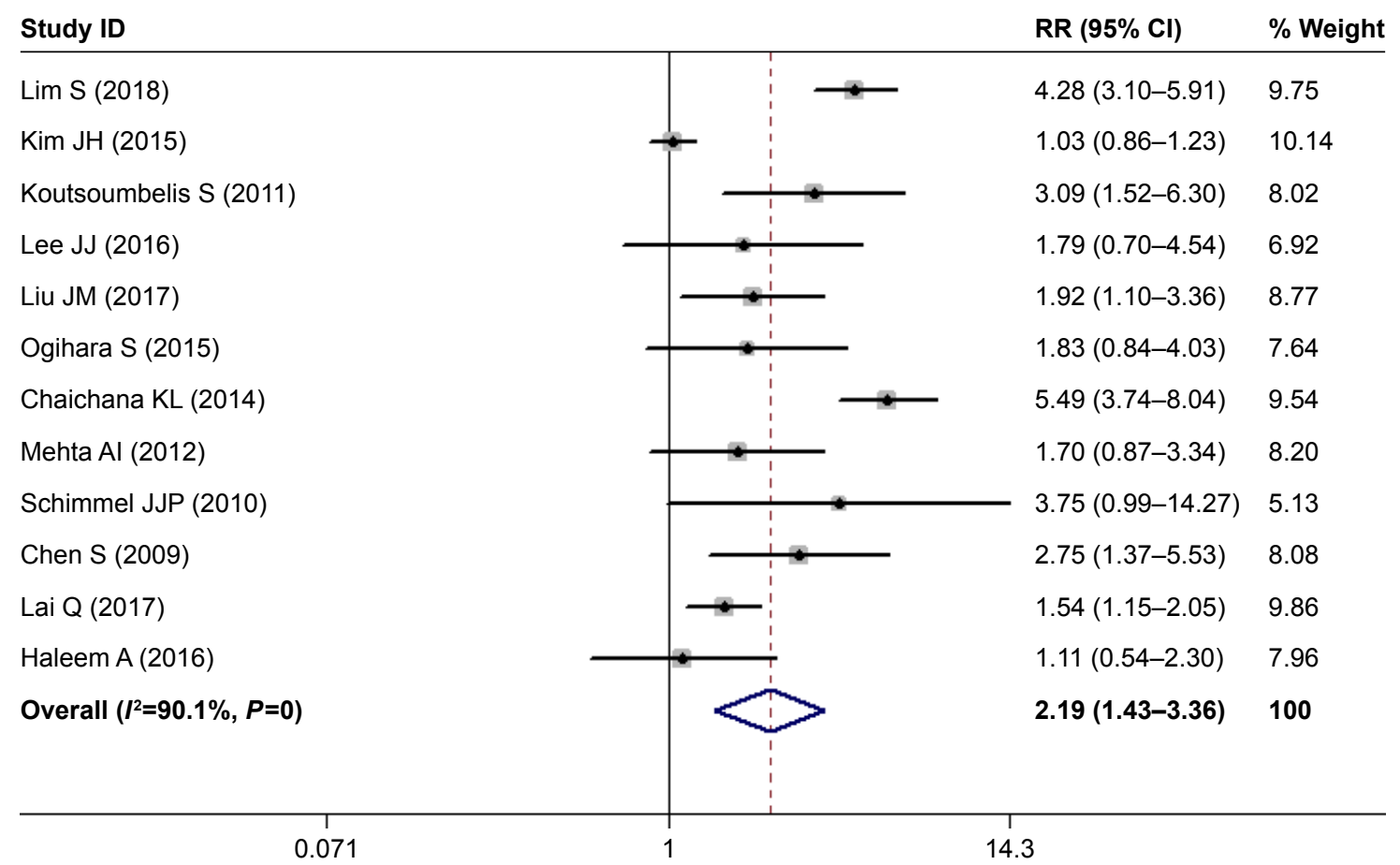

Figure 4 Forest plot showing the relationship between diabetes and postoperative surgical site infection.

Note: Weights are from random-effects analysis.

increased risk for SSI. Heterogeneity was not significant $\left(I^{2}=33.9 \%, P=0.267\right)$.

\section{Duration of hospital stay}

Five studies investigated the relationship between duration of hospital stay and postoperative SSI. ${ }^{30,31,35,37,41}$ Pooled estimates suggested that patients with longer hospital stay had a higher risk of SSI (WMD 2.07 days, 95\% CI 0.28-3.87; $P=0.024$ ). This indicated that prolonged hospital stays increased the risk of SSI. Heterogeneity was not significant $\left(I^{2}=29.6 \%, P=0.384\right)$.

\section{Estimated blood loss}

Four studies investigated the relationship between estimated blood loss and postoperative SSI. ${ }^{33,37,41,42}$ The pooled result

\begin{tabular}{|c|c|c|}
\hline Study ID & $\operatorname{RR}(95 \% \mathrm{Cl})$ & $\%$ Weight \\
\hline Lim S (2018) & $0.73(0.53-1.00)$ & 39.02 \\
\hline Habiba S (2017) & $0.87(0.54-1.41)$ & 12.55 \\
\hline Koutsoumbelis S (2011) & $0.69(0.34-1.41)$ & 8.08 \\
\hline Lee JJ (2016) & $1.09(0.51-2.33)$ & 3.85 \\
\hline Ogihara S (2015) & $1.36(0.55-3.35)$ & 2.72 \\
\hline Chaichana KL (2014) & $1.08(0.58-2.03)$ & 6.59 \\
\hline Petilon JM (2012) & $1.33(0.53-3.38)$ & 2.80 \\
\hline Schimmel JJP (2010) & $1.60(1.10-2.32)$ & 9.23 \\
\hline Haleem A (2016) & $0.69(0.43-1.12)$ & 15.18 \\
\hline Overall $\left(I^{2}=46.2 \%, P=0.062\right)$ & $0.89(0.75-1.06)$ & 100 \\
\hline
\end{tabular}

Figure 5 Forest plot showing the relationship between current smoking and postoperative surgical site infection. 
showed that patients with greater blood loss had a higher risk of SSI (WMD $106.9 \mathrm{~mL}, 95 \%$ CI 65.14-278.53); however, this was not significant $(P=0.224)$. This indicated that increased blood loss was not a significant risk factor for SSI in patients who had undergone lumbar spine surgery. Heterogeneity was not significant $\left(I^{2}=44.2 \%, P=0.0698\right)$.

\section{Chronic obstructive pulmonary disease}

Five studies investigated the relationship between COPD and postoperative SSI. ${ }^{28,31,39,42,43}$ Pooled estimates suggested that patients with COPD had a similar rate of SSI as those without (RR 1.21, 95\% CI 0.68-2.17; $P=0.521$ ). This indicated that COPD was not a significant risk factor for SSI in patients who had undergone lumbar spine surgery. Heterogeneity was not significant $\left(I^{2}=13.8 \%, P=0.292\right)$.

\section{Publication bias}

Assessment of publication bias using Begg's and Egger's tests showed that there was no potential publication bias across the included studies (Egger's test, $P=0.473$; Begg's test, $P=0.527$ ).

\section{Discussion}

The present study was a meta-analysis of eligible studies with the objective of identifying risk factors for SSI following lumbar spinal surgery. Our study suggested that female sex, diabetes, obesity, BMI, pronged operation time, prolonged hospital stay, hypertension, and previous surgery were risk factors for SSI in patients who had undergone lumbar spinal surgery, whereas, current smoking, ASA grade $>2$, increased age, COPD, cardiovascular disease, rheumatoid arthritis, and osteoporosis were not.

To the best of our knowledge, this is the first comprehensive meta-analysis to investigate risk factors for SSI in patients who have undergone lumbar spinal surgery. Our study indicated that patients with diabetes had a 2.19-fold increased risk of developing postoperative SSI compared with those without. Findings from the present study were consistent with most of the studies included, except three, ${ }^{29,32,34}$ which found that diabetes was not a risk factor for SSI. Lee et $\mathrm{al}^{32}$ retrospectively analyzed 149 adult patients who had undergone lumbar spine surgery with a midline posterior approach. Among these patients, 15 experienced postoperative SSI and 134 had no infection. ${ }^{32}$ The prevalence of patients with diabetes in the SSI and non-SSI groups was $26.7 \%$ (four of 15) and 14.9\% (20 of 134), respectively, which were not significant $(P=0.249) .{ }^{32}$ Similarly, Kim et $\mathrm{al}^{29}$ undertook a review of a case series to identify risk factors for SSI in posterior lumbar interbody fusion, and they also reported a negative relationship between diabetes and SSI. In that study, $80 \%$ (24 of 30) of patients in the SSI group had diabetes compared with $77.8 \%(1,401$ of 1,801$)$ in non-SSI group. ${ }^{29}$ However, in another retrospective study of 2,715 patients investigating risk factors for SSI following posterior lumber spinal surgery, the authors suggested that diabetes was an independent risk factor for SSI. ${ }^{33}$ The rate of diabetes in SSI and control groups was 25\% (16 of 64) and 13\% (25 of 192), respectively, which demonstrated that diabetes patients were at higher risk of developing SSI. ${ }^{33}$ The inconsistent results of these three studies are difficult for us to explain, since they all had large samples and used multivariate logistic regression analyses to reduce the influences of selection bias in retrospective studies.

In the present study, we found that obesity was a significant risk factor for SSI in patients who had undergone lumbar spinal surgery. These results were in line with previous studies. ${ }^{31,32,36}$ Koutsoumbelis et al collected 3,218 patients who had undergone posterior lumbar instrumented arthrodesis, ${ }^{31}$ and found that $42.9 \%$ (36 of 84) of them who developed SSI had obesity compared with 7.1\% (12 of 168) of patients who had no SSI. ${ }^{31}$ The OR for obesity was 9.75 (95\% CI 4.70-20.21, P<0.001), indicating that patients with obesity had 9.75-fold increased risk of developing SSI than those without. Consistent with these results, Lee et $\mathrm{al}^{32}$ reported that obesity was associated with a 4.09-fold increased risk of SSI (OR 4.09, 95\% CI 1.32-12.7; $P=0.015$ ). In that study, the obesity rate in the SSI and non-SSI groups was $66.7 \%$ (ten of 15 ) and $32.8 \%$ (44 of 134), respectively, which indicated that obese patients were more likely to develop SSI than normal patients. ${ }^{32}$ When obese patients are undergoing surgery, it is necessary to cut through a large amount of oily liquid. The surgical incision is filled with sterile gauze, and bacteria can become embedded in the incision. ${ }^{42}$ This increases the risk of infection. Moreover, previous studies ${ }^{2,44}$ have demonstrated that BMI is a risk factor for postoperative complications: when BMI is increased by $5 \mathrm{~kg} / \mathrm{m}^{2}$, the risk of postoperative SSI is accordingly increased by $10 \%$.

Consistently with prior studies, prolonged operations were significantly associated with postoperative SSI. ${ }^{29,31,33}$ Kim et $\mathrm{al}^{29}$ analyzed 1,831 patients who had undergone posterior lumbar interbody fusion, and found that SSI patients had had longer surgery than those in the non-SSI group. In that study, operation times in SSI and non-SSI groups were 195.3 minutes and 177.1 minutes $(P=0.008)$, respectively, ${ }^{29}$ suggesting that prolonged surgery increased the risk of SSI. Similar results were found in another study, which assessed risk factors for SSI among patients with posterior lumbar instrumented arthrodesis. ${ }^{31}$ In that study, the duration of 
surgery in SSI and non-SSI groups was 373.1 \pm 167.1 minutes and 291.6 \pm 130.7 minutes, respectively. ${ }^{31}$ The difference between them was significant $(P<0.001)$, which confirmed the role of prolonged surgery in postoperative SSI. However, in another case-control study, ${ }^{37}$ a negative relationship was found between duration of surgery and SSI. In that study, the authors performed a propensity-score-matched case-control study of 60 patients who had undergone instrumented lumbar fusion. ${ }^{37}$ The operating time for SSI patients was less (259.27 minutes) than non-SSI patients (288.17), and the difference between them was not significant $(P=0.298) .{ }^{37}$ The negative result might be explained by the small sample.

Previous surgery was another risk factor for SSI, and this result was comparable to previous studies. ${ }^{35,39}$ Ogihara et al performed prospective multicenter surveillance to determine the risk factors for SSI in adult patients who had undergone lumbar spinal surgery. ${ }^{34}$ They enrolled 2,736 patients, and $24(0.9 \%)$ developed SSI. ${ }^{34}$ The prevalence of patients who had had previous surgery in deep SSI and nondeep SSI groups was $29.2 \%$ and $15.5 \%$, respectively, suggesting that previous surgery was an increased risk for postoperative SSI. ${ }^{34}$ Chaichana et al performed a study with 817 consecutive cases, and found previous surgery was associated with 2.994fold increased risk of SSI (RR 2.994, 95\% CI 1.26-9.35; $P=0.009) .{ }^{35}$ It was assumed that patients who had had previous lumbar spine surgery typically had longer surgeries, which increased procedural complexity and propensity for durotomies, thereby increasing the risk of SSI. ${ }^{45}$

\section{Limitations}

This study has several potential limitations. First, in some outcomes, substantial heterogeneity was identified among the included studies. Despite sensitivity analysis being performed to detect potential sources of heterogeneity, no valuable information was found. Second, most of the studies were conducted with a retrospective design, and their results might be biased by the inherent disadvantages. This may have had a potential impact on our pooled estimates.

\section{Conclusion}

Our study indicates that female sex, diabetes, obesity, BMI, prolonged operation, prolonged hospital stay, hypertension, and previous surgery are independent risk factors for SSI following lumbar spine surgery, whereas, current smoking, ASA grade $>2$, increased age, COPD, cardiovascular disease, rheumatoid arthritis, and osteoporosis are not. Knowing these risk factors, surgeons could adequately analyze and evaluate risk factors in patients, and then develop prevention measurements to reduce the rate of SSI.

\section{Disclosure}

The authors report no conflicts of interest in this work.

\section{References}

1. Fei Q, Li J, Lin J, et al. Risk Factors for Surgical Site Infection After Spinal Surgery: A Meta-Analysis. World Neurosurg. 2016;95:507-515.

2. Olsen MA, Nepple JJ, Riew KD, et al. Risk factors for surgical site infection following orthopaedic spinal operations. J Bone Joint Surg Am. 2008;90(1):62-69.

3. Wang TY, Back AG, Hompe E, Wall K, Gottfried ON. Impact of surgical site infection and surgical debridement on lumbar arthrodesis: A single-institution analysis of incidence and risk factors. $J$ Clin Neurosci. 2017;39:164-169.

4. Pull Ter Gunne AF, Mohamed AS, Skolasky RL, van Laarhoven CJ, Cohen DB. The presentation, incidence, etiology, and treatment of surgical site infections after spinal surgery. Spine. 2010;35(13):1323-1328.

5. Calderone RR, Garland DE, Capen DA, Oster H. Cost of medical care for postoperative spinal infections. Orthop Clin North Am. 1996;27(1): 171-182.

6. de Lissovoy G, Fraeman K, Hutchins V, Murphy D, Song D, Vaughn BB. Surgical site infection: incidence and impact on hospital utilization and treatment costs. Am J Infect Control. 2009;37(5):387-397.

7. Veeravagu A, Patil CG, Lad SP, Boakye M. Risk factors for postoperative spinal wound infections after spinal decompression and fusion surgeries. Spine. 2009;34(17):1869-1872.

8. Satake K, Kanemura T, Matsumoto A, Yamaguchi H, Ishikawa Y. Predisposing factors for surgical site infection of spinal instrumentation surgery for diabetes patients. Eur Spine J. 2013;22(8):1854-1858.

9. Jiang J, Teng Y, Fan Z, Khan S, Xia Y. Does obesity affect the surgical outcome and complication rates of spinal surgery? A meta-analysis. Clin Orthop Relat Res. 2014;472(3):968-975.

10. Meng F, Cao J, Meng X. Risk factors for surgical site infections following spinal surgery. J Clin Neurosci. 2015;22(12):1862-1866.

11. Fang A, Hu SS, Endres N, Bradford DS. Risk factors for infection after spinal surgery. Spine. 2005;30(12):1460-1465.

12. Sasso RC, Garrido BJ. Postoperative spinal wound infections. $J$ Am Acad Orthop Surg. 2008;16(6):330-337.

13. Classen DC, Evans RS, Pestotnik SL, Horn SD, Menlove RL, Burke JP. The timing of prophylactic administration of antibiotics and the risk of surgical-wound infection. $N$ Engl J Med. 1992;326(5):281-286.

14. Lee J, Singletary R, Schmader K, Anderson DJ, Bolognesi M, Kaye KS. Surgical site infection in the elderly following orthopaedic surgery. Risk factors and outcomes. J Bone Joint Surg Am. 2006;88(8):1705-1712.

15. Moher D, Liberati A, Tetzlaff J, Altman DG. Preferred reporting items for systematic reviews and meta-analyses: the PRISMA statement. BMJ. 2009;339:b2535.

16. Wells G, Shea B, O'Connell D, Peterson J, Welch V. The NewcastleOttawa Scale (NOS) for assessing the quality of nonrandomized studies in meta-analyses. In: 3rd Symposium on Systematic Reviews: Beyond the Basics; Jul 3-5. 2000; Oxford, UK.

17. Mantel N, Haenszel W. Statistical aspects of the analysis of data from retrospective studies of disease. J Natl Cancer Inst. 1959;22(4):719-748.

18. Dersimonian R, Laird N. Meta-analysis in clinical trials. Control Clin Trials. 1986;7(3):177-188.

19. Higgins JP, Thompson SG, Deeks JJ, Altman DG. Measuring inconsistency in meta-analyses. BMJ. 2003;327(7414):557-560.

20. Begg CB, Mazumdar M. Operating characteristics of a rank correlation test for publication bias. Biometrics. 1994;50(4):1088-1101.

21. Egger M, Davey Smith G, Schneider M, Minder C. Bias in meta-analysis detected by a simple, graphical test. BMJ. 1997;315(7109):629-634. 
22. Kim BD, Hsu WK, de Oliveira GS, Saha S, Kim JY. Operative duration as an independent risk factor for postoperative complications in single-level lumbar fusion: an analysis of 4588 surgical cases. Spine. 2014;39(6):510-520.

23. Klemencsics I, Lazary A, Szoverfi Z, Bozsodi A, Eltes P, Varga PP. Risk factors for surgical site infection in elective routine degenerative lumbar surgeries. Spine J. 2016;16(11):1377-1383.

24. Tsubouchi N, Fujibayashi S, Otsuki B, et al. Risk factors for implant removal after spinal surgical site infection. Eur Spine J. Epub 2017 Sep 14.

25. Asomugha EU, Miller JA, Mclain RF. Surgical Site Infections in Posterior Lumbar Surgery: A Controlled-Cohort Study of Epidural Steroid Paste. Spine. 2017;42(1):63-69.

26. Golubovsky JL, Ilyas H, Chen J, Tanenbaum JE, Mroz TE, Steinmetz MP. Risk factors and associated complications for postoperative urinary retention after lumbar surgery for lumbar spinal stenosis. Spine J. 2018;18(9):1533-1539.

27. Glassman S, Carreon LY, Andersen M, et al. Predictors of Hospital Readmission and Surgical Site Infection in the United States, Denmark, and Japan: Is Risk Stratification a Universal Language? Spine. 2017; 42(17):1311-1315.

28. Lim S, Edelstein AI, Patel AA, Kim BD, Kim JYS, Jys K. Risk Factors for Postoperative Infections After Single-Level Lumbar Fusion Surgery. Spine. 2018;43(3):215-222.

29. Kim JH, Ahn DK, Kim JW, Kim GW. Particular Features of Surgical Site Infection in Posterior Lumbar Interbody Fusion. Clin Orthop Surg. 2015;7(3):337-343.

30. Habiba S, Nygaard ØP, Brox JI, Hellum C, Austevoll IM, Solberg TK. Risk factors for surgical site infections among 1,772 patients operated on for lumbar disc herniation: a multicentre observational registry-based study. Acta Neurochir. 2017;159(6):1113-1118.

31. Koutsoumbelis S, Hughes AP, Girardi FP, et al. Risk factors for postoperative infection following posterior lumbar instrumented arthrodesis J Bone Joint Surg Am. 2011;93(17):1627-1633.

32. Lee JJ, Odeh KI, Holcombe SA, et al. Fat Thickness as a Risk Factor for Infection in Lumbar Spine Surgery. Orthopedics. 2016;39(6): e1124-e1128.

33. Liu JM, Deng HL, Chen XY, et al. Risk Factors for Surgical Site Infection After Posterior Lumbar Spinal Surgery. Spine. 2018;43(10): $732-737$.
34. Ogihara S, Yamazaki T, Maruyama T, et al. Prospective multicenter surveillance and risk factor analysis of deep surgical site infection after posterior thoracic and/or lumbar spinal surgery in adults. J Orthop Sci. 2015;20(1):71-77.

35. Chaichana KL, Bydon M, Santiago-Dieppa DR, et al. Risk of infection following posterior instrumented lumbar fusion for degenerative spine disease in 817 consecutive cases. J Neurosurg Spine. 2014;20(1):45-52.

36. Mehta AI, Babu R, Karikari IO, et al. 2012 Young Investigator Award winner: The distribution of body mass as a significant risk factor for lumbar spinal fusion postoperative infections. Spine. 2012;37(19): $1652-1656$.

37. Petilon JM, Glassman SD, Dimar JR, Carreon LY. Clinical outcomes after lumbar fusion complicated by deep wound infection: a case-control study. Spine. 2012;37(16):1370-1374.

38. Falavigna A, Righesso O, Traynelis VC, Teles AR, da Silva PG. Effect of deep wound infection following lumbar arthrodesis for degenerative disc disease on long-term outcome: a prospective study: clinical article. J Neurosurg Spine. 2011;15(4):399-403.

39. Schimmel JJ, Horsting PP, de Kleuver M, Wonders G, van Limbeek J. Risk factors for deep surgical site infections after spinal fusion. Eur Spine J. 2010;19(10):1711-1719.

40. Chen S, Anderson MV, Cheng WK, Wongworawat MD. Diabetes associated with increased surgical site infections in spinal arthrodesis. Clin Orthop Relat Res. 2009;467(7):1670-1673.

41. Blam OG, Vaccaro AR, Vanichkachorn JS, et al. Risk factors for surgical site infection in the patient with spinal injury. Spine. 2003;28(13): $1475-1480$.

42. Lai Q, Song Q, Guo R, et al. Risk factors for acute surgical site infections after lumbar surgery: a retrospective study. J Orthop Surg Res. 2017;12(1):116.

43. Haleem A, Chiang HY, Vodela R, et al. Risk Factors for Surgical Site Infections Following Adult Spine Operations. Infect Control Hosp Epidemiol. 2016;37(12):1458-1467.

44. Collins I, Wilson-Macdonald J, Chami G, et al. The diagnosis and management of infection following instrumented spinal fusion. Eur Spine J. 2008;17(3):445-450.

45. Wimmer C, Gluch H, Franzreb M, Ogon M. Predisposing factors for infection in spine surgery: a survey of 850 spinal procedures. $J$ Spinal Disord. 1998;11(2):124-128.
Therapeutics and Clinical Risk Management

\section{Publish your work in this journal}

Therapeutics and Clinical Risk Management is an international, peerreviewed journal of clinical therapeutics and risk management, focusing on concise rapid reporting of clinical studies in all therapeutic areas outcomes, safety, and programs for the effective, safe, and sustained use of medicines. This journal is indexed on PubMed Central, CAS,

\section{Dovepress}

EMBase, Scopus and the Elsevier Bibliographic databases. The manuscript management system is completely online and includes a very quick and fair peer-review system, which is all easy to use. Visit http://www.dovepress.com/testimonials.php to read real quotes from published authors. 